\title{
¿Qué tan musical es el hombre?
}

\author{
John Blacking
}

John Blacking estudió antropología y arqueología en el King’s College de Inglaterra. Desde su infancia hizo estudios de piano. En 1964 ocupó el puesto de musicólogo en la Biblioteca de Música Africana en Johannesburgo, Sudáfrica. En sus primeros estudios explicó el movimiento del cuerpo y la música. En 1956 hizo estudios de campo en el grupo étnico venda de Sibasa, nación bantu en el Transvaal al norte de Sudáfrica. En 1967 publicó su libro Canciones de los niños venda, una de las etnografías musicales funcionalistas más importantes. En esta obra plantea el concepto de "análisis cultural" como el estudio de la interrelación sistemática total entre el contexto cultural y la música. En 1970 trabajó como jefe del Departamento de Antropología Social de la Queen's University de Belfast. Durante 1971 dictó conferencias magistrales John Danz en la Universidad de Washington, mismas que dieron lugar a la edición de su libro ¿Qué tan musical es el hombre? Una de las preocupaciones centrales del autor fue hacer conciencia de la relación complementaria que debe existir en la práctica etnomusicológica entre el estudio de las técnicas "performativas" o de ejecución de la música y el estudio de la cultura que produce la música. Falleció el 24 de enero de 1990.

LA MÚSICA EN LA SOCIEDADY LA CULTURA

$\mathrm{H}$ e definido la música como un sonido humanamente organizado. He discutido que deberíamos buscar relaciones entre los patrones de conducta humana y los patrones de sonido producidos como resultado de la interacción de una organización. Reforcé esta afirmación al referirme a los conceptos de música que comparten los venda del Transvaal del Norte. Los venda también comparten la experiencia de "hacer" música, y sin esta experiencia habría muy poca música. La producción de los patrones de sonido que los venda llaman música depende, primero, de la continuidad de los grupos sociales que la ejecutan y, en segundo lugar, de la forma en que los miembros de esos grupos se relacionan entre sí.
Para poder averiguar qué es la música y qué tan musical es el hombre, necesitamos preguntar quién escucha, y quién toca y canta en una sociedad dada, y preguntarnos por qué. Éste es un cuestionamiento sociológico, y dentro de diferentes sociedades las situaciones pueden compararse sin hacer referencia a las formas de música superficiales porque estamos preocupados únicamente en su función dentro de la vida social. A este respecto, quizá las diferencias entre música negra, música country y western, rock y pop, óperas, música sinfónica y canto llano sean poco significativas. Lo que desmotiva a un hombre puede "emocionar" a otro, y esto no se debe a ninguna calidad absoluta en la música en sí sino que tiene que ver con el significado que ha alcanzado como miembro de una cultura o grupo social en particular. No debemos perder de vista que, aun cuando todos tenemos

Desacatos, núm. 12, otoño 2003, pp. 149-162.

Este artículo fue publicado originalmente en John Blacking, ¿How Musical is Man?,

University of Washington Press, Seattle y Londres, 1973.

- Traducción de Brigitte Sanabria. 
nuestras preferencias personales, no podemos juzgar la efectividad de la música o los sentimientos de los músicos por la influencia que tiene sobre las personas. Si un maestro de iniciación venda, viejo y ciego, escucha en silencio una grabación del canto de iniciación domba, no podemos juzgar que la pieza es más o menos efectiva que una grabación de Spokes Mashiyane's Penny Whistle Band de Johannesburgo, la cual lo aburre a él pero emociona a su nieto. No podemos decir que los kwakiutl son más emotivos que los hopi porque su estilo de danza nos parece más extático. En algunas culturas, o en ciertos tipos de música y danza dentro de una cultura, las emociones se pueden interiorizar deliberadamente, lo cual no significa que sean menos intensas. Las experiencias sicodélicas o místicas de un hombre no pueden ser vistas ni sentidas por sus vecinos, pero no por esto pueden ser desechadas por considerarlas irrelevantes para la vida del sujeto en cuestión dentro de la sociedad.

El mismo criterio de juicio debe aplicarse a las aparentes diferencias en la complejidad superficial de la música, la cual tendemos a observar en los mismos términos que se relaciona la creciente complejidad de los coches, los aviones y muchas otras máquinas con su nivel de eficiencia como medios de comunicación, es muy común asumir que la evolución técnica de la música y las artes debe ser signo de una expresión más profunda y mejorada. Sugiero que la popularidad que tiene cierta música de la India en Europa o América no está desligada del hecho de que parece ser al mismo tiempo técnicamente brillante y agradable al oído, y estar acompañada de un profundo proceso filosófico. Cuando intento interesar a mis alumnos en los sonidos de la música africana, sé que aun yo tiendo a enfocar su atención en las proezas técnicas de la ejecución porque estas son apreciables de inmediato. Y aún así la simplicidad o complejidad de la música es, al final, irrelevante, la ecuación no debe ser: menos = mejor o más = mejor; sino que debería ser: más o menos = diferente. Lo que realmente "conmueve" a las personas es el contenido humano de los sonidos humanamente organizados. Incluso si esto surge como una melodía o armonía exquisita, como un "objeto sónico", si se quiere llamar así, de todos modos empezó como una concep- ción de un ser humano sensible, y es esta sensibilidad la que puede incitar (o no) los sentimientos de otro ser humano, de una manera muy parecida con la que las ondas magnéticas conducen una conversación telefónica de un hablante a otro.

Este tema de la complejidad musical sólo se vuelve importante cuando intentamos valorar la musicalidad en el humano. Supongamos que argumento que, debido a que existen sociedades cuyos miembros son tan competentes musicalmente como todas las personas lo son usando el lenguaje, la música puede ser una cualidad característica de la especie humana. Con toda seguridad alguien va a rebatir y decir que la evidencia de una distribución muy generalizada de la habilidad para escuchar y ejecutar música entre los venda y otras sociedades aparentemente musicales, no debe compararse con la limitada distribución de la facilidad musical en, digamos, Inglaterra, porque la complejidad de la música inglesa es tal que sólo pocos pueden lograr su dominio. Puesto con otras palabras, si la música inglesa fuera tan elemental como la música venda, entonces, por supuesto que los ingleses parecerían ser tan universalmente musicales como los venda. La implicación más general de este argumento es que el desarrollo tecnológico trae consigo un cierto grado de exclusión social. Ser una audiencia pasiva es el precio que algunos tienen que pagar para ser miembros de una sociedad superior cuya superioridad se sostiene en la habilidad excepcional de un limitado grupo de elegidos. Entonces aparece el tema del nivel técnico de lo que se define como musicalidad, dando lugar a la necesidad de clasificar a algunos como no musicales. Es en estas suposiciones que la habilidad musical se alienta o se anestesia dentro de muchas sociedades industriales modernas. Estos supuestos son diametralmente opuestos a la idea de los venda de que todo ser humano normal tiene la capacidad de la ejecución musical.

El tema de la complejidad musical es irrelevante para cualquier consideración dentro del ámbito de la competencia musical universal. En primer lugar, dentro de un sistema musical único, la complejidad externa más amplia puede ser considerada como una extensión de vocabulario, la cual no altera los principios básicos de su gramática y la falta de significado fuera de este contexto. 
En segundo lugar, al comparar diferentes sistemas no podemos asumir que la complejidad externa es musical o cognitivamente más compleja. En cualquier caso, la mente de un ser humano es infinitamente más complicada que cualquier cosa producida por hombres o culturas en particular. Y sobre todo, la eficacia funcional de la música parece ser más importante para los escuchas que la complejidad o simplicidad exterior. ¿De qué sirve ser el pianista más virtuoso del planeta o componer la música más ingeniosa, si nadie quiere escucharla?, ¿qué caso tiene para el humano crear o utilizar sonidos nuevos sólo para sí mismo? Dentro de la cultura venda, ¿tienen algún significado los sonidos nuevos, por ejemplo, en términos de grupos nuevos y cambio social?, ¿para qué cantar y bailar?, ¿de qué sirve mejorar la técnica musical si el objeto final de una presentación musical es compartir una experiencia social?

Las funciones de la música dentro de la sociedad pueden ser los factores decisivos que promuevan o inhiban un talento musical latente, al igual que afectan la elección de conceptos culturales y materiales con los cuales se compone la música. No podremos explicar los principios de la composición y los efectos de la música hasta que hayamos entendido mejor la relación entre la experiencia músical y la humana. Si describo algunas de las funciones de la música en la sociedad venda, quizá este nuevo conocimiento estimule una mejor comprensión de procesos similares en otras sociedades. Ésta ha sido ciertamente mi propia experiencia. Desde mi primera estancia de dos años en el distrito Sibasa entre 1956 y 1958, y como resultado de mi trabajo de campo subsecuente en otras partes de África, he llegado a entender mi propia sociedad de una manera más clara y he aprendido a apreciar más mi propia música. Desconozco si mis análisis de la música venda son correctos. Me he beneficiado grandemente de las críticas de los venda quienes han tenido a bien discutir conmigo mis evidencias y conclusiones, pero pueden existir otras interpretaciones que hasta la fecha se nos han escapado. Sea cual sea el juicio final de mi análisis de la música de los venda, espero que mis descubrimientos desempeñen un papel aunque sea pequeño en la recuperación de las condiciones de dignidad y libertad dentro de las cuales se desarrolló originalmente su tradición musical.
Existen cerca de 300 ooo venda, y la mayoría de ellos viven en un área rural subdesarrollada que les fue dejada después de que colonizadores blancos tomaran posesión del resto de sus tierras para establecer granjas y abrir minas. Comparados con más de doce millones de sudafricanos negros, divididos casi en partes iguales entre los grupos lingüisticos zulú, xhosa y soto-tswana, los venda pueden parecer insignificantes. Sin embargo, el gobierno sudafricano blanco ha mostrado gran interés en ellos y ha llevado a cabo un importante ejercicio militar en su llamada tierra natal. Los venda viven en las montañas Zoutpansberg y sus alrededores, justo al sur del río Limpopo, la frontera norte de la república blanca de África del Sur. Desde que estuve allí en 1958, cada vez más blancos se están asentando en tierras antes reservadas para los negros.

En 1899 los venda fueron los últimos sudafricanos en someterse a la ley boer. Bien podrían ser los primeros en adquirir su independencia total. Los ancestros de algunos clanes venda vivieron en Venda mucho antes que los blancos llegaran al Cabo, y consiguieron mantener su identidad aún después de aceptar al gobierno de invasores negros que vinieron del norte hace 200 años. Los venda son pacifistas de corazón y tienen un dicho que dice así: "Mudi wa gozwi a u na malila" ("En la residencia del cobarde no hay llanto"). Posteriormente, cuando su país fue invadido desde el sur por negros que huían del avance de los blancos, los venda prefirieron retirarse a la seguridad de sus montañas y esperar a que los invasores se fueran. Se negaron a aceptar innovaciones culturales y a incorporar a los extraños a su sistema político en condiciones en las que pudieran disminuir en su sociedad, en vez de aumentar, valores como la cooperación y el "humanismo" (vluthu). Por otra parte, durante la segunda parte del siglo XIX, los venda adoptaron y aceptaron como "canciones de la gente que habla venda" varias canciones y estilos extranjeros de los vecinos del norte $y$ del sur.

Puede parecer sorprendente que un pueblo tan musical haya mostrado tan poco interés - y comparativamente poca habilidad- en los sonidos y técnicas de la música europea. Las razones son en parte técnicas, pero principalmente políticas. En primer lugar, el tipo de 
música que se diseminó en las misiones y las escuelas generalmente fue del tipo más monótono de música institucional europea, y aun la mejor música ha sido invariablemente distorsionada por la forma en que ha sido enseñada por los blancos. No ha habido contacto real con el original de esta lengua extraña. Ninguno de los europeos que enseñaron la tradición eran músicos consumados, así es que tanto ellos como los africanos a los que formaron como maestros con frecuencia se mostraban tan inseguros como sus alumnos acerca de cuál era la lectura correcta de las partituras. Expertos "blancos" les aseguraban que el sentimiento y expresión (lo que en muchas ocasiones se resume a usar uniformes brillantes en competencias de canto intercolegiales) eran más importantes que la precisión. Esta es una noción bastante extraña para la cultura musical venda, en donde siempre se espera exactitud y donde el sentimiento es algo asumido, pero fue lo suficientemente fuerte para producir resultados desastrosos en el proceso de asimilación de la música europea, y no es sorprendente que los aparentemente musicales venda hayan fallado en destacar en la ción de las niñas, cada vez que una novicia es llevada al río o a su choza de iniciación, las mujeres y niñas que la acompañan le advierten a la gente que se vienen acercando con una canción especial, en donde el labio inferior es sacudido con el dedo índice:

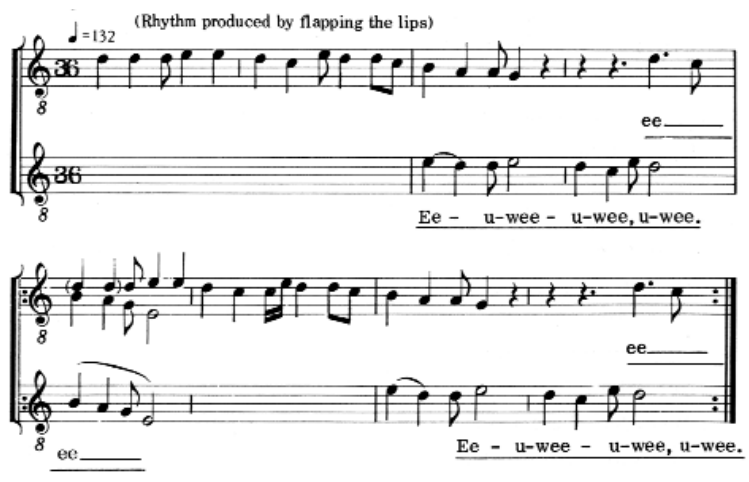

La siguiente canción, con su preludio poco común, indica que una novicia es sacada de su casa y llevada para ser iniciada. La melodía puede ser reconocida hasta por mujeres que no pueden escuchar las palabras:

taban realmente interesados.

Probablemente los factores políticos eran más significativos que las barreras técnicas que he descrito. Aunque el Evangelio y la educación que los misioneros trajeron a los venda fueron bien recibidas al principio, la administración blanca y la explotación comercial que se generó no lo fue. Desde 1900 los venda no han podido retirarse a la protección de sus montañas, como lo hicieron con los primeros invasores. Han sido obligados por una fuerza superior a soportar un sistema autoritario que contradice la democracia tradicional africana. Por lo tanto, ¿es sorprendente que la indiferencia y hasta hostilidad contra la música europea acompañe su resistencia contra la dominación blanca? La reacción general ante la música europea es mantenerse dentro de la función musical de su sociedad, y debe ser abordada como un fenómeno tanto sociológico como musical.

Parte de la música de los venda es incidental, y su ejecución es el signo de actividad de los grupos sociales. La mayoría de los adultos venda saben lo que está pasando simplemente con escuchar los sonidos. Durante la inicia-
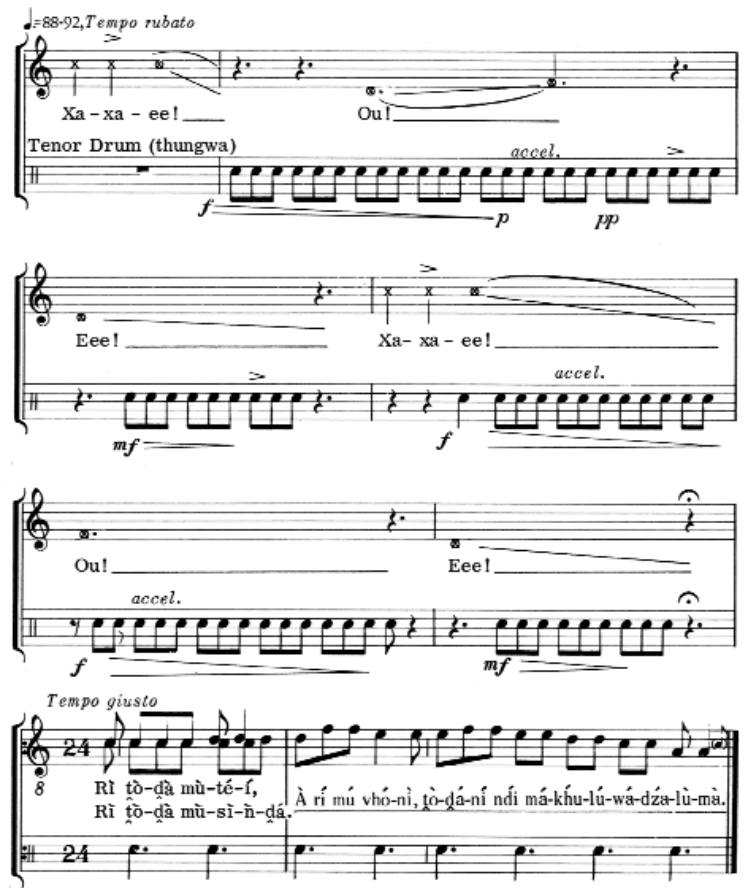
Durante las distintas etapas de las escuelas de niñas, la enseñanza se imparte directa e indirectamente por medio de danzas simbólicas, que suelen ser ejercicios físicos extenuantes, ejecutados al son de una variedad de complejos ritmos. Una canción les indica a las niñas que no deben chismear:

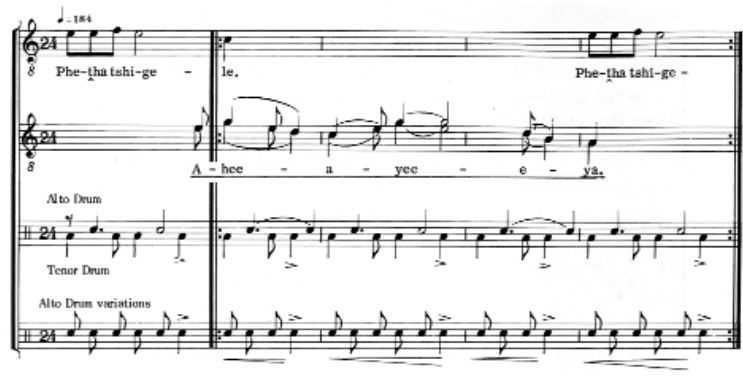

Los venda aprenden a entender los sonidos de la música como entienden el lenguaje. Pueden identificar no menos de 16 estilos distintos, con diferentes ritmos y combinaciones de cantantes e instrumentos; y dentro de estos estilos hay subdivisiones de estilo, al igual que diferentes canciones dentro de cada división. Por ejemplo, en la escuela de iniciación para niñas sungwi existen cuatro tipos principales de cantos:

1. Nyimbo dza u sevhetha ("canciones para danzar alrededor"). Las cantan las niñas en una rueda que gira alrededor de los tambores en sentido opuesto a las manecillas del reloj. El ritmo de la canción es rápido y se canta con más frecuencia que otro tipo de canciones en la escuela. Junto a ésta, existen otras dos con ritmos especiales: una canción "de despedida” (luimbo Iwa u edela, que quiere decir literalmente "canción para dormir"), la cual siempre da por terminada una sesión; $y$ una canción de reclutamiento (luimbo Iwa u wedza, que quiere decir literalmente "canción para ayudar a una persona a cruzar el río"), que se canta cuando los miembros de mayor rango van reclutando.

2. Nyimbo dza vhahwira ("canciones de los bailarines enmascarados"). Se cantan cuando los bailarines enmascarados se presentan ante las niñas. El ritmo varía, con episodios rápidos o lentos, para acompañar las diferentes fases de la danza con ritmos característicos que marcan los distintos pasos.

3. Nyimbo dza dzingoma ("canciones para rituales especiales"). Acompañan ciertas pruebas severas que las novicias tienen que pasar cuando están en el segundo nivel de la iniciación. Cada una tiene un patrón rítmico que la distingue.

4. Nyimbo dza milayo ("canciones de las leyes de la escuela"). Las cantan las novicias y cualquier otra graduada que esté presente. Se hincan en el suelo cerca de los tambores mientras la muluvhe, la chica a cargo de las novicias, encabeza el canto.

La figura 1 (página 156) resume los diferentes tipos de música de la comunidad que los venda reconocen e indica las temporadas del año en que se pueden o no tocar.

Aunque generalmente los venda clasifican su música de acuerdo con la función social, y que el nombre dado a cada función y la música que le corresponde generalmente es el mismo, el criterio de discriminación es al mismo tiempo formal y musical. La función de la música se reconoce basándose en el sonido, particularmente en su ritmo y en la conformación de su ensamble vocal y/o instrumental. Los contextos dentro de los cuales se canta una canción no son exclusivos, pero la forma en que se canta la canción está generalmente determinada por el contexto. Así, una canción de la cerveza de raíz puede ser adaptada como una canción de juego para la iniciación domba de las niñas, en cuyo caso se añadirá un acompañamiento de tambor y la forma llamado-respuesta puede ser transformada en una secuencia de frases melódicas entrelazadas. De la misma manera, una serie de transformaciones de la danza nacional, tshikona, pueden ser interpretadas con instrumentos musicales venda. Todas suenan de manera diferente pero todas son llamadas tshikona y se perciben como variaciones de un mismo tema en los "lenguajes" de diferentes instrumentos.

Cuando los venda discuten o clasifican diferentes tipos de canciones, generalmente hacen una distinción entre canciones que son apropiadas para una función en particular y aquellas que han sido adoptadas y adaptadas. Considero que éste es un fenómeno común en el centro 


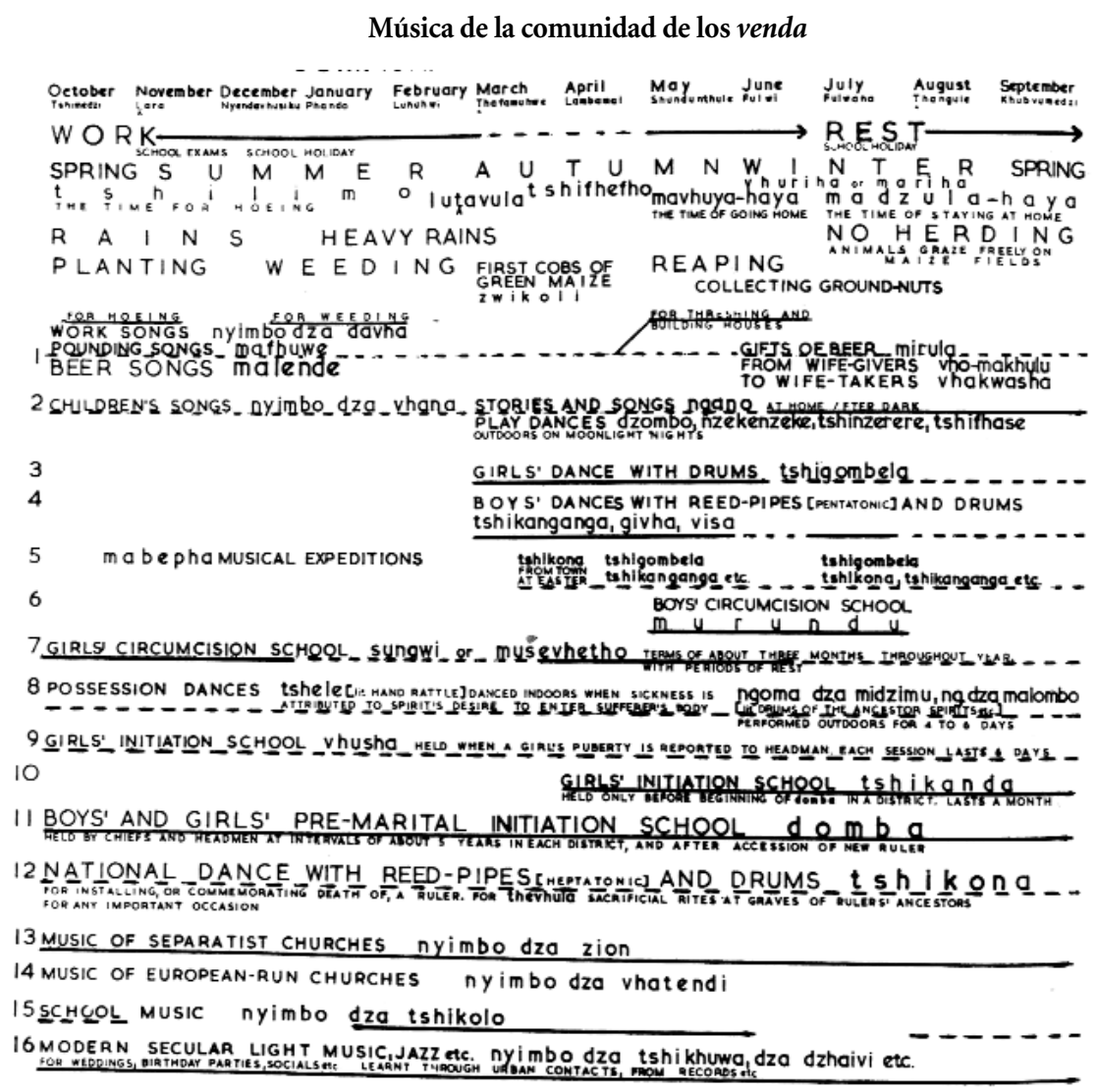

Figura 1. Diagrama que muestra los diferentes tipos de música de la comunidad reconocida por los venda, e indicación de las épocas del año cuando se pueden o no ejecutar.

y sur de África, que debe ser cuidadosamente estudiado por los investigadores de campo. Mencionaré un ejemplo particularmente bueno que me encontré cuando estaba trabajando en el Gwembe Tonga de Zambia. Grabé lo que se me describió como una "canción de la molienda" y el contexto me dejó sin dudas sobre su función. En un contexto diferente, la misma melodía se me describió como mankuntu, "canción de baile para gente joven", y de nuevo, el contexto me dejó sin dudas sobre su función. La única diferencia entre las dos ejecuciones se encontraba en el ritmo, cadencia y contexto social. La canción no era en realidad para la molienda, sino una canción que se entona mientras se muele. Resultó ser una canción de baile mankuntu que era popular en esos momentos, y el uso que le daban las mujeres al moler es comparable a cantar "Hark, the Herald Angels Sing" mientras se lava la vajilla después de la cena de Navidad.

La clasificación que dan las personas a las canciones por su forma o su función puede ser una evidencia importante de los procesos de transformación musicales y extra-musicales que se aceptan dentro de las sociedades. También puede ser relevante en la valoración de los efectos de la música. Por ejemplo, existe una canción venda sobre la soledad y la muerte que escuché entonada con muchas ganas en una fiesta, sin el menor rastro de tristeza. En otra ocasión estaba charlando con un maestro de iniciación, viejo y ciego, quien comenzó a entonar la misma canción. Estaba a punto de pararse a bailar cuando su hijo lo detuvo diciéndole: "No bailes, hombre viejo." Debido a que su padre estaba cantando una canción 


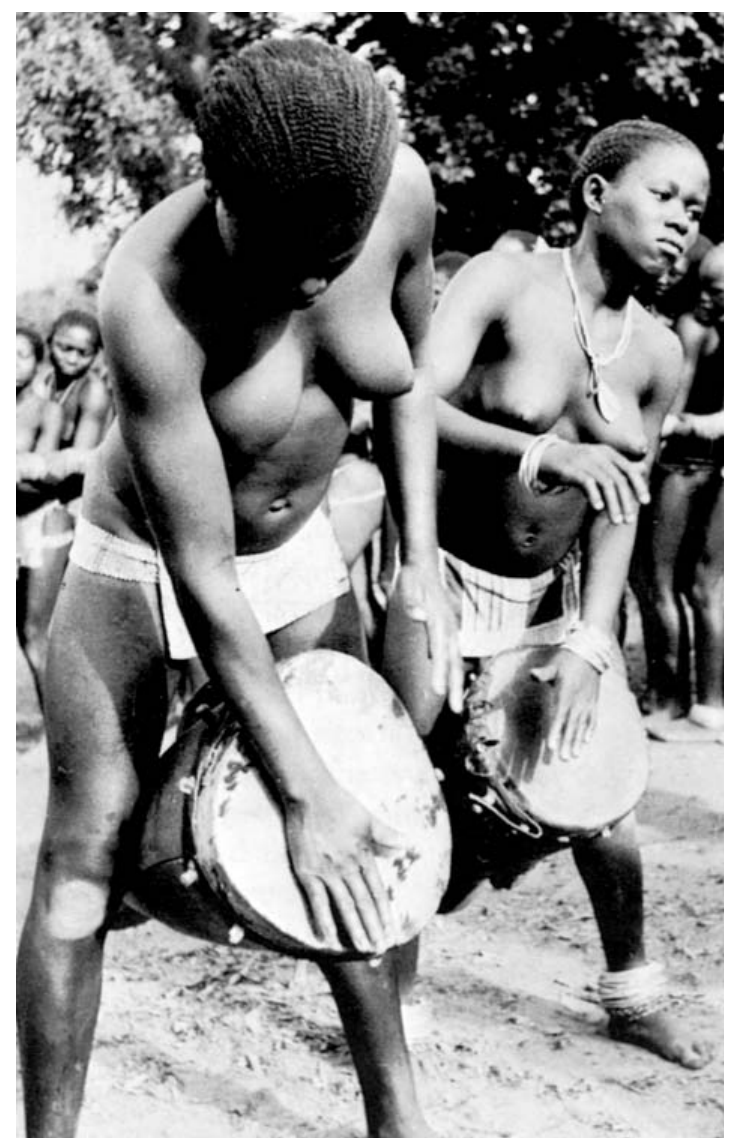

Niñas venda practican la primera parte del baile tshigombela.

triste, debía estar lleno de tristeza y no tenía caso intensificar la emoción bailando, sobre todo cuando existía el riesgo de que se cayese y se lastimase. El hijo estaba profundamente conmovido, pero cuando le pregunté acerca de la canción simplemente respondió que era una canción de la cerveza de raíz. Pudo haberla descrito como "una canción de la tristeza", pero prefirió darle su clasificación formal.

El valor de la música en la sociedad y sus efectos diferenciadores en la gente pueden constituir factores esenciales en el desarrollo o atrofia de las habilidades musicales; el interés de las personas puede ser que se centre menos en la música en sí y más en las actividades sociales con las que se le asocia. Por otro lado, la habilidad musical no podría nunca desarrollarse si no tuviese la ayuda de la motivación extra-musical. Por cada infante prodigio cuyo interés y habilidad se perdieron por no poder relacionar su música con la vida en sociedad, debe haber miles de personas que aman la música ahora debido a una experiencia de vida y sienten profundamente haber descuidado la práctica de tal o cual instrumento o no haber sido enseñados a tocar uno. Este conflicto ha sido aligerado por algunos programas musicales, pero la combinación de actividades sociales, físicas y musicales no es tan completa como en la sociedad venda. Mientras observaba a los jóvenes venda desarrollar sus cuerpos, sus amistades y su sensibilidad a través de los bailes de la comunidad, no pude dejar de lamentar las cientos de tardes que desperdicié en el campo de rugby y en los cuadriláteros de box. Pero yo fui criado no para cooperar sino para competir; hasta la música se consideraba más como una experiencia competitiva que compartida.

Aunque la estructura de gran parte de la música venda exige un alto nivel de cooperación para ser ejecutada, sería erróneo sugerir que toda la música y las experiencias sociales asociadas con la música son compartidas en forma equitativa. Por ejemplo, en el último día de la iniciación tshikanda de las niñas, el sombrío, silencioso comportamiento de las novicias contrasta fuertemente con el excitado canto y baile de las mujeres mayores a cargo de éstas y de los otros graduados presentes. A pesar de que las niñas deben aparentar un estado de humildad y desprendimiento, es difícil de creer que estén escondiendo otra cosa que no sea resignación e indiferencia a la música que deben interpretar. Cuando les pregunté sobre sus reacciones, detecté una diferencia significativa entre la respuesta de las niñas de "es la costumbre" y la respuesta de los adultos "es la costumbre, está bien".

De igual manera, los excitantes ritmos de la danza de posesión de los venda (ngoma dza midzumi) no ponen en trance a todos los venda. Sólo ponen en trance a miembros del culto, y sólo cuando están bailando en sus propias casas, con lo cual únicamente son poseídos por los espíritus familiares. El efecto de la música depende del contexto dentro del cual es interpretada y escuchada. Pero a final de cuenta depende de la música en sí, tal como lo descubrí una vez cuando estaba tocando uno de los tambores. Los bailarines toman turno para entrar al 


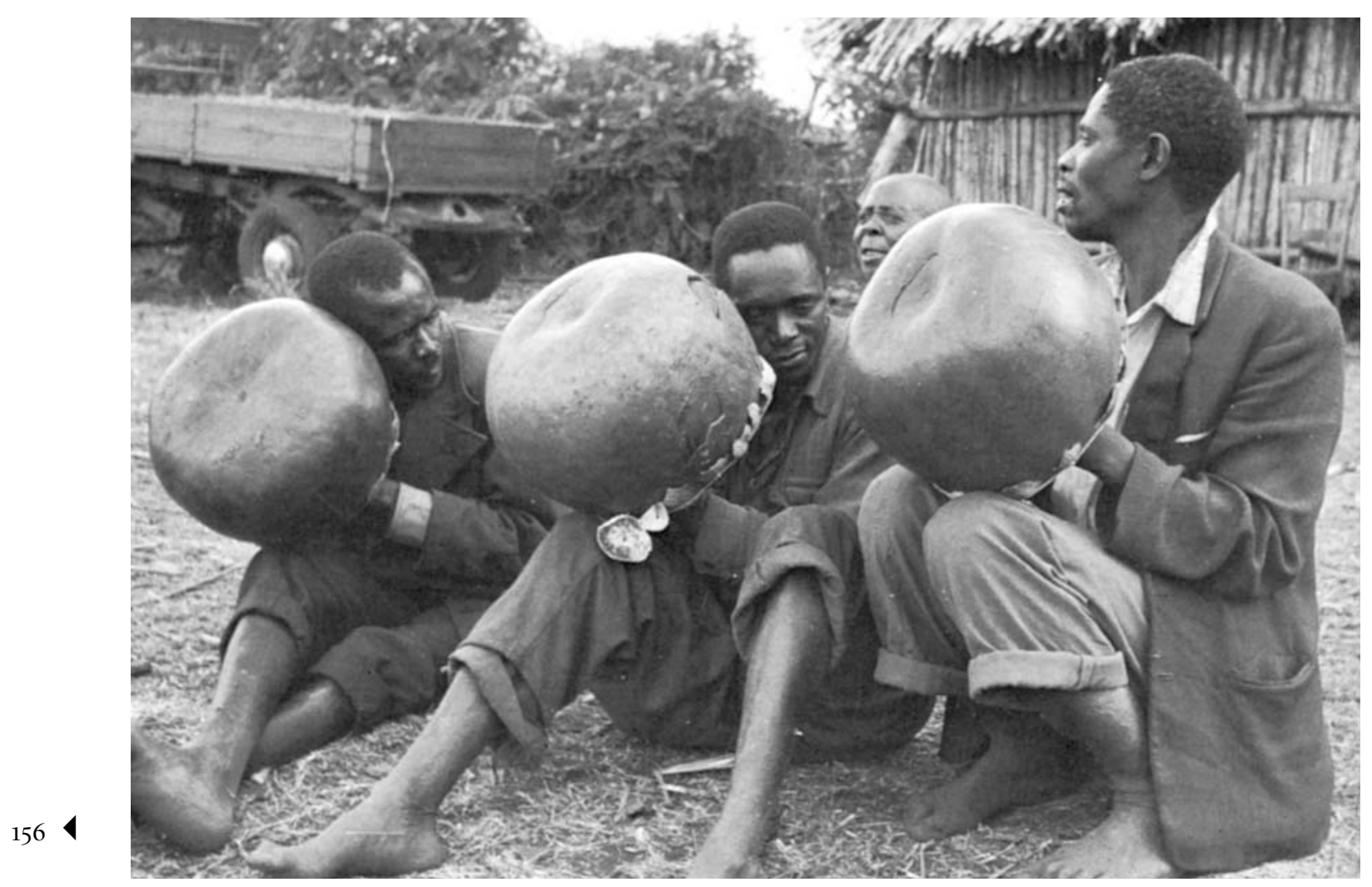

Un trío con grandes mbiras (mbila dza madeza).

"círculo" y al principio no hubo quejas sobre mis esfuerzos interpretativos. No obstante, muy pronto una mujer mayor comenzó a danzar y se esperaba que ella entrara en trance porque la música se estaba tocando para su grupo de culto. Sin embargo, después de algunos minutos se detuvo e insistió que otro debía reemplazarme en el tambor. Argumentaba que yo estaba arruinando el efecto de la música al acelerar el ritmo - lo suficiente, supongo- como para inhibir el comienzo del trance.

La forma en la que la música de la danza de posesión se vuelve efectiva sugiere que el parentesco es un factor tan importante como el ritmo de la música respecto a los efectos que causa en las personas. Pero los factores decisivos no son tanto los lazos sanguíneos como sus implicaciones sociales, ni tampoco la música sino el entorno social y las actitudes desarrolladas hacia éste. Después de todo, si la música de la danza de la posesión tiene el po- der de poner en trance a una mujer en una ocasión, ¿por qué no abría de hacerlo en otra? ¿Es la situación social la que inhibe los —de otra manera- poderosos efectos de la música? ¿O es que la música es impotente sin el reforzamiento de un conjunto especial de circunstancias sociales?

Evidencias de esta naturaleza me hacen ser escéptico ante las pruebas de asociación musical que se aplican a sujetos en condiciones artificiales y asociales, nunca imaginadas por los creadores de la música. Bajo estas condiciones, la música no puede evitar convertirse en una creación sin significado, o por lo menos, sus significados son irremediablemente diversos.

También saca a la luz otra pregunta. Dado que la música no puede expresar nada extra-musical a menos que la experiencia a la cual se refiere ya exista en la mente del escucha, ¿puede comunicarse aunque sea algo a las 


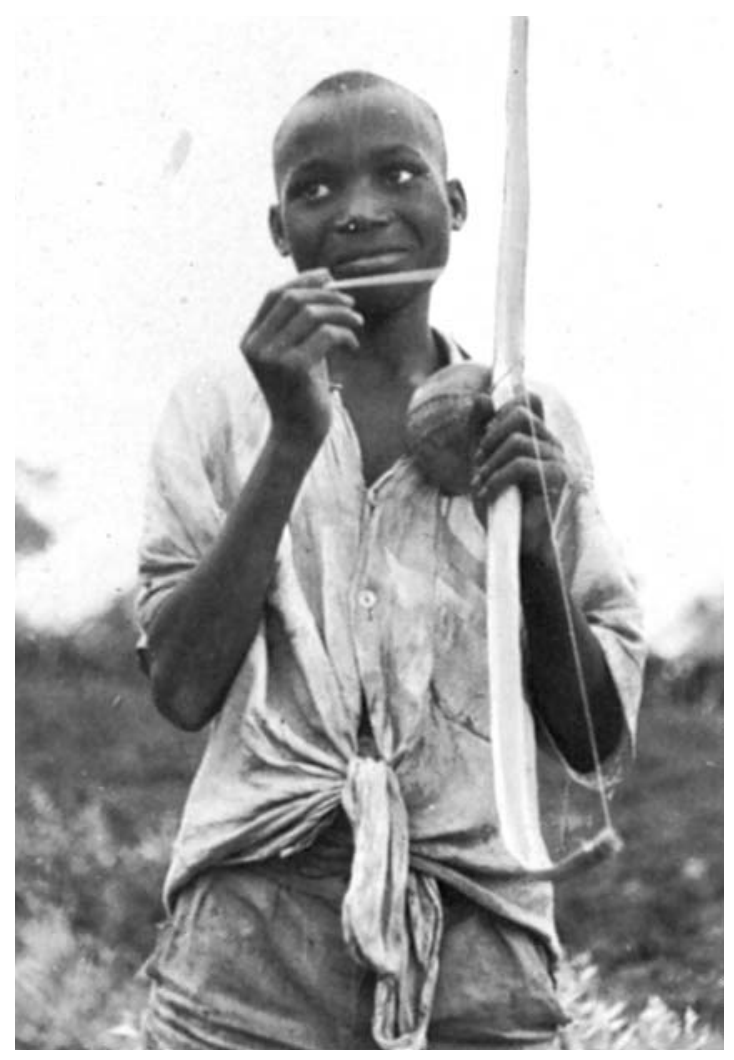

Arco musical dende.

mentes no preparadas y no receptivas? ¿No puede ni siquiera un ritmo poderoso emocionar a un sujeto no preparado? ¿O es que las mujeres venda no se conmueven con la música porque no están dispuestas a dejarse conmover? No puedo contestar estas incógnitas, pero mi propio amor por la música y mi convicción de que es más que un comportamiento aprendido, me hacen confiar en que lo que sucede es que las inhibiciones sociales son muy poderosas y no que la música carezca de poder.

Volvamos al tema del parentesco en el desarrollo de la habilidad musical. Puede que los venda no consideren la posibilidad de que existan hombres no musicales, pero sí reconocen que existen personas que interpretan mejor la música que otras. Su juicio se basa en el despliegue de brillantez técnica y originalidad del intérprete, y también en el vigor y confianza de su ejecución. Se considera que cualquiera que se tome la molestia de perfeccionar su técnica lo hace porque es una persona profundamente dedicada a la música como medio para poder compartir algún tipo de experiencia con sus compañeros. El deseo sincero de expresar un sentimiento no se acepta como una excusa para una ejecución inexacta o incompetente, como lo es en el confuso mundo de la música pop moderna y de la llamada folk. Si una persona quiere dedicarse a la música, se espera que lo haga bien. La habilidad del que toca el tambor principal (matsige) en un baile de procesión es calificado por los sonidos que produce, y no por las veces que remueve los ojos y contorsiona el cuerpo.

Los venda pueden sugerir que una habilidad musical excepcional es un carácter heredado biológicamente. Pero en la práctica reconocen que los factores sociales desempeñan el papel más importante en el desarrollo de la habilidad o su supresión. Por ejemplo, un niño de extracción noble puede mostrar gran talento, pero al crecer se esperará que abandone las presentaciones musicales regulares para dedicarse a una actividad más seria como es el gobierno. Esto no quiere decir que vaya a dejar de escuchar crítica e inteligentemente la música, de hecho, podría recibir importantes consejos para un gobierno exitoso a través de una pieza musical. Al contrario, una niña de extracción noble es motivada en todas las formas posibles para que desarrolle sus capacidades musicales, porque así de mayor podrá desempeñar un papel activo en la supervisión de las escuelas de iniciación de las niñas que se llevan a cabo en los hogares de los reinantes y para quienes la música es un complemento indispensable de sus funciones didácticas y rituales. Durante los dos meses en los que ensayan diariamente la pieza de danza para niñas, tshigombela, observé cómo las jóvenes parientes del jefe del grupo daban presentaciones destacadas, aunque al principio no mostraban ser más musicales que sus compañeras de la misma edad. Estoy seguro de que la clave de su desarrollo como bailarinas se debió a los elogios y el interés que les mostraron las mujeres en la audiencia, quienes eran, principalmente, de la familia del jefe, y que por este hecho conocían a las niñas por su nombre porque todas eran parientes. Con toda seguridad, fueron las consecuencias sociales de la relación sanguínea las que afectaron el crecimiento de su 
capacidad musical y no capacidades musicales heredadas genéticamente. De nuevo, no es sorprendente que los maestros de la iniciación tiendan a "heredar" esta destreza o facilidad de sus padres. Un maestro debe conocer muchos cantos y rituales, y por lo tanto, su hijo se encuentra en una posición favorecida cuando ayuda al padre en su trabajo.

En la sociedad venda, una habilidad musical excepcional es algo que se espera de la gente que nace en el seno de ciertas familias o grupos sociales en los que la ejecución musical es esencial para mantener la solidaridad del grupo. Así como la ejecución musical es el factor central que justifica la existencia continua de una orquesta como grupo social, también un grupo del culto de posesión venda o una escuela de iniciación domba o una escuela de niñas sungwi se desintegrarían si no existiera la música. De hecho, sólo una pequeña parte de los que nacen en el grupo correcto se distinguen como músicos excepcionales. Lo que parece diferenciarlos de los otros es que tienen una interpretación mejor porque le han dedicado más tiempo y energía. Cuando los venda den también el esfuerzo humano, y al poder reconocer la maestría dentro del medio musical, los escuchas revelan que su competencia musical general no es menor que aquella de los músicos a los que aplauden. Debemos recordar que la existencia de Bach y Beethoven depende tanto de las audiencias discernientes como de los ejecutantes. De la misma manera, algunos ancestros venda no pueden volver a sus hogares excepto por medio de la intervención de sus descendientes.

Aunque la música de la comunidad sea la que domina el escenario musical de los venda, y que los factores sociales sean los que influyen en el desarrollo de la habilidad musical, no deja de existir la creación musical individual, y buenos ejecutantes solistas pueden surgir sin que existan los incentivos que he descrito. Mujeres jóvenes en desarrollo confían en los calmados, íntimos tonos de un arco musical lugube o su equivalente moderno, el arpa de quijada. Los jóvenes cantan a los gozos y penas del amor haciéndose acompañar con un mbira - o con otro tipo de arco llamado tshihwana. Un tercer arco (dende) es tocado de manera común por músicos semi-profesionales quienes son notoriamente populares entre las mujeres.

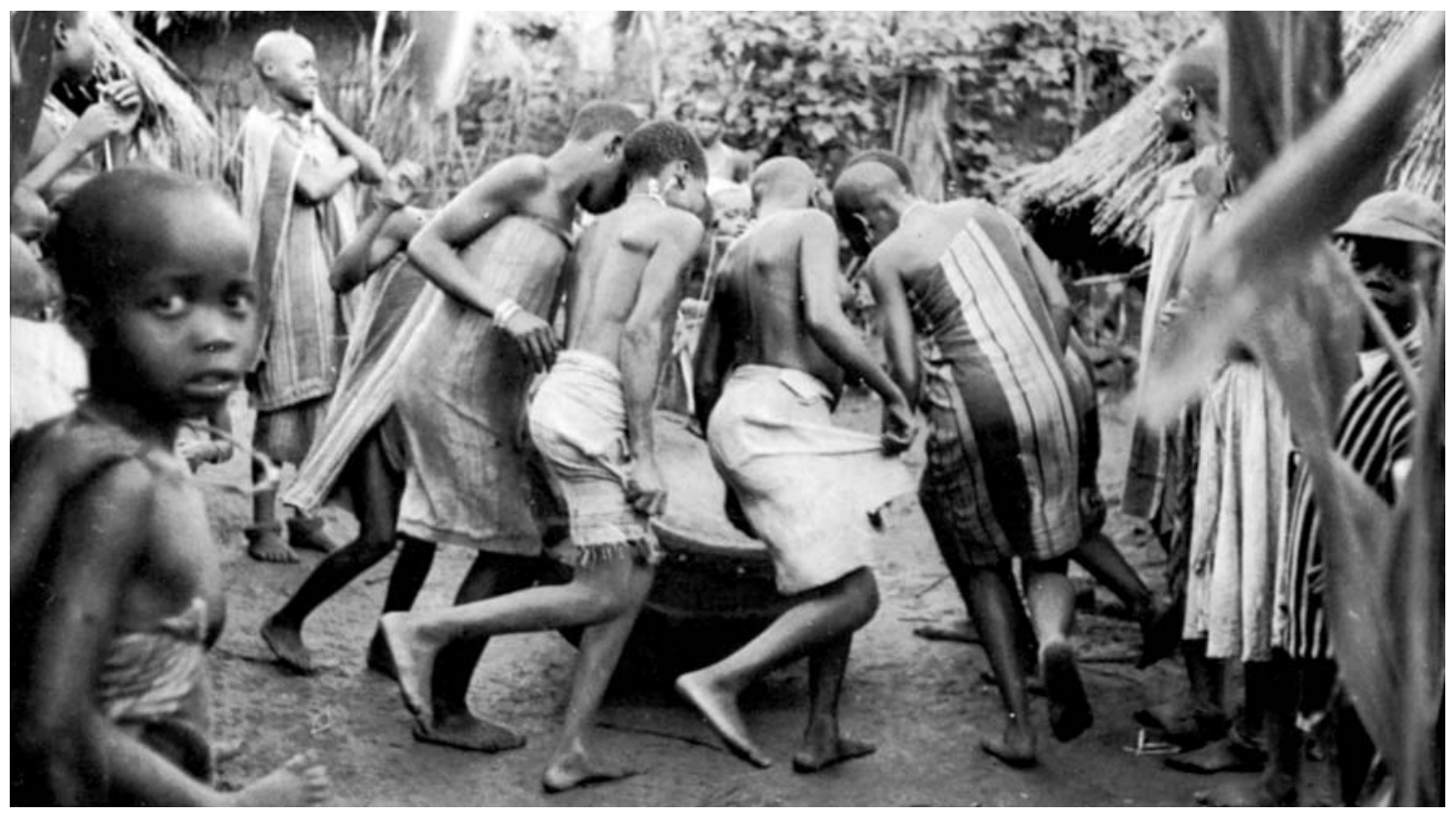

Niñas venda bailando un solo ( u gaya) durante la segunda parte del baile tshigombela. 


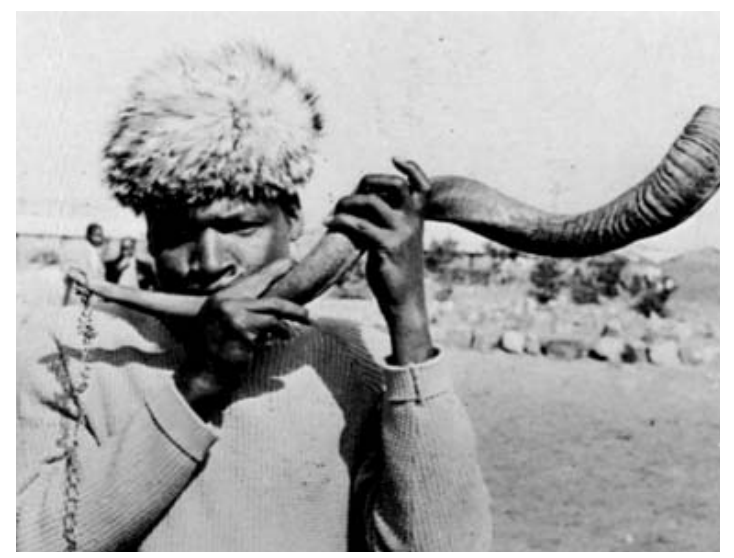

El cuerno para enviar señales, phalaphala, hecho con los cuernos de un antílope sable o $k u d u$.

El nombre dado a tales trovadores — tshilombe - se relaciona con la palabra que se refiere a la posesión por un espíritu, tal como tshilombo y malombo. Los venda reconocen que manifestaciones de habilidad musical pueden surgir en lugares inesperados y en los sujetos que menos se pensaba, pero insisten en que se les dé una explicación lógica. El término tshilombe debe tomarse, más que como una aclamación al genio o al talento excepcional, como una descripción ocupacional. Un músico individual sobresaliente es alguien que se pone en contacto con las fuerzas de los espíritus, como el médico o el miembro del culto de posesión, pudiendo así expresar un espectro más amplio de experiencias que la mayoría de la gente. Podrá parecer paradójico que sus habilidades creativas deban ser expresadas a través de la originalidad y cuidado de las palabras al componer que en la música misma. Pero existe una razón y ésta se encuentra en el balance de dos principios básicos de la música venda.

Como enfaticé en el primer capítulo, la música venda se distingue de la no-música por la creación de un mundo de tiempo especial. La principal función de la música es involucrar a las personas en experiencias compartidas dentro del marco de su experiencia cultural. La forma que toma la música debe servir para esta función. Así, en el curso normal de eventos, la música venda se convierte en algo más musical y menos relativo a la cultura, cuando esto es posible, y se abandonan las restricciones de las palabras para dar paso a una expresión musical más libre de los individuos dentro de la comunidad. Para asegurar que esta forma no pierda su función esencial, el proceso se invierte en las composiciones de ciertas personas. La función de tales composiciones es impactar y expandir la conciencia de la audiencia venda al reflejar y contradecir el espíritu del tiempo. Reflejan los intereses políticos de un máximo número de personas al contradecir las tendencias musicales a las cuales están acostumbradas. El mismo tipo de análisis de la efectividad musical puede aplicarse a otros contextos. No consideraría que es una exageración decir que Beethoven adquirió su extraordinario poder musical al ser antimusical y al escandalizar a la sociedad de su época. Quizá sus contemporáneos pudieron haber sido más musicales en el tratamiento de la melodía, por ejemplo. Pero su tipo de musicalidad convencional era menos relevante para los problemas contemporáneos aunque fuera una consecuencia lógica de los procesos cognitivos temporales.

Analizar la composición y apreciación musical en términos de su función social y los procesos cognitivos que pueden aplicarse en otros campos de la actividad humana no resta - de ninguna manera - importancia a la música en sí, y está alineada con la costumbre común de interrelacionar una serie de actividades humanas y llamarlas artes. Sin embargo, en esta etapa tan temprana de la investigación, tenemos que tener cuidado de no asumir que la música siempre es creada por los mismos procesos, o que sus procesos están especialmente relacionados con los utilizados en otras artes. Los procesos que en una cultura se aplican al lenguaje o a la música pueden aplicarse en otra a las relaciones de parentesco o a la organización de la economía.

Resultará útil hacer una distinción entre los diferentes tipos de comunicación musical, los cuales pueden describirse de forma amplia como los usos utilitarios y artísticos de la música dentro de la sociedad venda. Por la forma en que se expresan los venda queda claro que para ellos no toda la música tiene el mismo valor. Toda su música crece a partir de las experiencias humanas y tiene una función directa sobre la vida social, pero sólo parte de ella se considera como lo que John Dewey ha llamado "un instrumento indispensable para la transformación del hombre y su mundo”. 


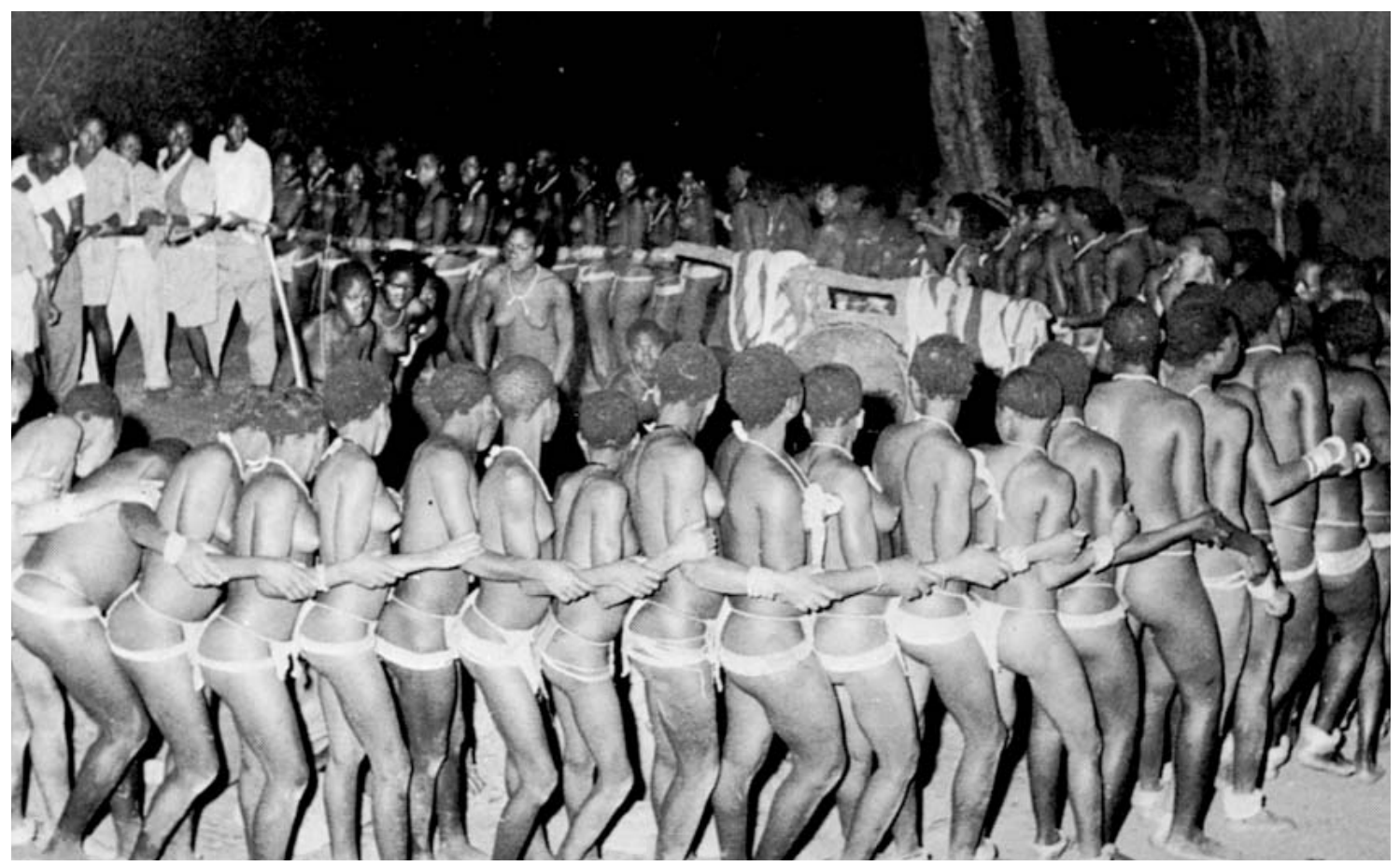

La danza de la escuela de iniciación domba de los venda.

Como lo han demostrado mis ejemplos, la música ven$d a$ es meramente una señal o signo de eventos sociales y tan utilitaria como los jingles de comerciales, spots de estaciones de radio, algunos tipos de música incidental y los himnos o canciones que son esencialmente distintivos de los diferentes grupos sociales. Muchos de los cantos de iniciación son más importantes como elementos marcadores de las diferentes etapas dentro de un ritual o como reforzadores o mnemónicos de lecciones que como experiencias musicales. Las canciones de trabajo coordinan y aligeran la carga, y un grupo especial de cantos de la cerveza de raíz puede usarse para manifestar quejas y hacer peticiones cuando grupos de mujeres llevan como presente una bebida gaseosa hecha de raíces a los hogares de sus suegros. En los cantos para la molienda de las mujeres, en algunas canciones para niños y en canciones de protesta, una estructura musical puede ritualizar la comunicación de tal forma que los mensajes se transmiten sin que se produzca una reacción contraria. No vas a prisión si lo expresas a través de la música, y quizá tu queja sea atendida porque fue la expresión de un creciente sentimiento público.

Es tentador definir las funciones utilitarias de la música de los venda como aquellas funciones en donde los efectos de la música son incidentales en el impacto de la situación social, y las funciones artísticas como aquellas donde la música en sí es un elemento crucial en la experiencia. El testimonio de los valores importantes relacionados con la tshikona, el baile nacional, y la aparente ejecución anti-musical presentada por expertos conocedores no contradice este argumento cuando nos damos cuenta de que es el proceso de creación musical el que se valora tanto, y en ocasiones hasta más que el producto final. Siento que el valor de la música se encuentra en las experiencias humanas que estuvieron involucradas en su creación. Existe una diferencia entre la música de ocasión y la que intensifica la conciencia humana, entre la música que simplemente se posee y la que sirve para existir. Creo que la primera tiene que ver con una factura buena, pero la segunda es arte, sin importar lo sim- 
ple o complejo que pueda sonar, y sin importar bajo qué circunstancias se produzca.

La música de tshikona expresa el valor del grupo social en general que despierta en los venda un sentido de pertenencia. Su ejecución involucra la mayor cantidad posible de personas, y su música involucra un número de tonos mayor que cualquier otra pieza de música venda que incorpora a más de uno o dos ejecutantes. Debido a lo que he dicho sobre las experiencias compartidas dentro de la música venda, debe quedar claro que la tshikona tiene valor y belleza para los venda, no sólo por la cantidad de personas y tonos involucrados, sino también por la cantidad de relaciones que deben establecerse entre las personas y los tonos cada vez que se ejecute. La música tshikona sólo puede producirse cuando veinte o más personas entonan flautas en diferentes tonos, con una precisión que depende de que cada individuo sostenga su propia parte al mismo tiempo que logre armonizar con las de los demás, además de que al menos cuatro mujeres toquen diferentes tambores entretejiendo una armonía polirítmica. Inclusive, la música tshikona no puede completarse a menos que los hombres lleven a cabo al unísono los diferentes pasos que el director de danza dirige de vez en cuando.

Lo que hace que la tshikona funcione no es un caso de más $=$ mejor: es un ejemplo de la producción máxima de energía humana disponible en una situación que genera el más alto nivel de individualidad en la comunidad más grande posible de individuos. Tshikona brinda una experiencia de lo mejor de todos los mundos posibles, $y$ los venda están totalmente concientes de su valor. Tshikona, dicen, es iwa-ha-masia-khali-i-tshi-vhila, "el momento en que la gente corre a la escena del baile y dejan que sus ollas se derramen". "Tshikona hace que los enfermos se sientan mejor y los viejos tiren sus bastones y se pongan a bailar". Tshikona "trae la paz al campo". De todas las experiencias compartidas dentro de la sociedad $v e n d a$, se dice que una presentación de tshikona es la que mayor valor tiene: la danza se conecta con ritos de adoración ancestrales y ocasiones de estados de trance, incorporando así a los vivos y a los muertos. Es la expresión más universal dentro de la música venda.

Debido a que la música puede crear un mundo de tiem- po virtual, Gustav Mahler dijo de ella que puede llevarnos al "otro mundo", el mundo en donde las cosas dejan de estar sujetas al tiempo y al espacio. Los balineses hablan de "la otra mente", refiriéndose al estado que podemos alcanzar a través de la danza y la música. Hacen referencia a estados donde la gente se da agudamente cuenta de la verdadera naturaleza de su ser, del "otro yo" dentro de ellos mismos y los otros seres humanos, y su relación con el mundo que los rodea. La vejez, la muerte, la pena, la sed, el hambre y otras aflicciones de este mundo se consideran eventos transitorios. La libertad existe fuera del tiempo presente y se produce una absorción completa en el "ahora sin tiempo del espíritu divino", la pérdida del ser en el estar. En ocasiones sentimos una experiencia más intensa de vida cuando nuestras vidas normales son perturbadas, y apreciamos más la calidad que la duración de tiempo que pasamos haciendo. El tiempo virtual de la música puede ayudar a generar tales experiencias.

Existe emoción en el ritmo y en la progresión del sonido organizado, en la tensión y relajación de la armonía o melodía, en la evolución acumulativa de la fuga, o en las infinitas variaciones en el tema con su movimiento desde y hacia el centro de un tono. El movimiento de la música en sí parece despertar en nuestros cuerpos todo tipo de respuestas. Y aún así la respuesta de las personas ante la música no puede explicarse por completo sin hacer referencia a la experiencia que tienen dentro de la cultura en la cual estas notas son signos y símbolos. Si una pieza musical mueve las emociones de una variedad de escuchas, probablemente esto no se deba a su forma exterior sino a lo que esta forma significa para cada escucha en términos de la experiencia humana. La misma pieza musical puede conmover a diferentes personas más o menos de la misma forma pero por razones diferentes. Usted podrá disfrutar de un canto llano porque es un católico romano o porque le gusta cómo suena ese tipo de música. No necesita tener buen oído para disfrutarlo como católico, ni tiene que ser creyente para disfrutarlo como música. En ambos casos, disfrutar la pieza tiene que ver con lo que se ha vivido dentro de la experiencia humana.

Incluso si una persona describiera sus experiencias musicales en el lenguaje técnico de la música, de hecho 


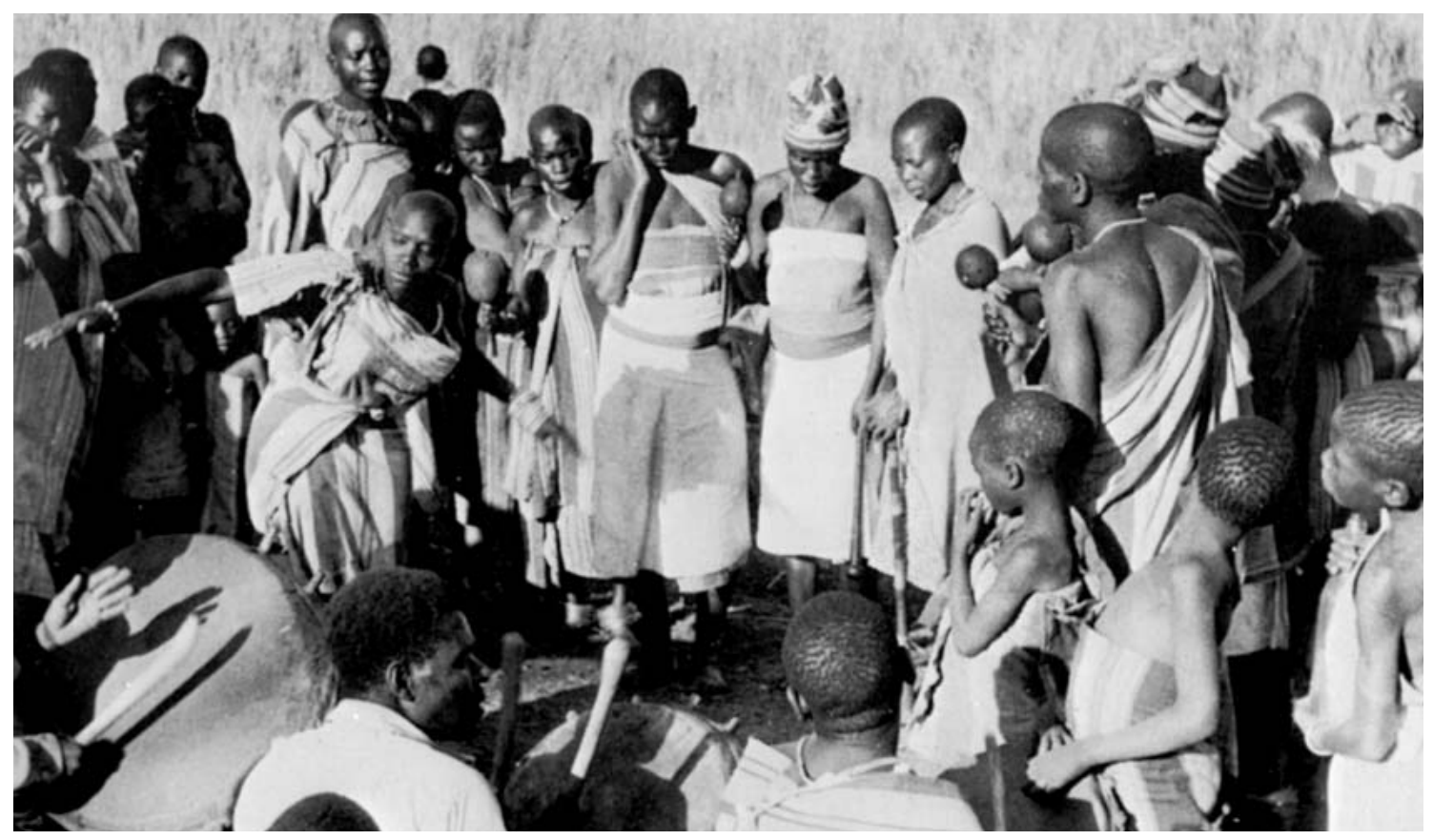

Ngoma dza midzimu, danza venda de la posesión de los espíritus. La niña jorobada que está bailando en el ruedo no será poseída por los espíritus ya que no pertenece a esta secta en particular. Los que han sido poseídos utilizan un uniforme especial y una especie de maraca.

estaría describiendo experiencias emocionales que aprendió a asociar con patrones particulares de sonido. Si otra persona describe su experiencia dentro de la misma tradición musical, podría estar describiendo una experiencia emocional — si no igual- muy parecida. La terminología musical puede ser un lenguaje con el cual describir la experiencia emocional humana, del mismo modo que ser miembro de un culto de posesión venda ofrece un cierto tipo de experiencia y una forma de hablar de la misma. Por lo tanto, bajo ciertas condiciones, el sonido de la música puede evocar un estado de conciencia que ha sido adquirido a través de procesos de experiencia social. Ya sea que el agente real es una situación social dada, como en el caso del culto de posesión venda, o una situación musical precisa, como en el caso de la respuesta de dos músicos que tuvieron una formación musical parecida, ésta es efectiva sólo por las asociaciones entre ciertas experiencias individuales y culturales.

Estoy seguro de que muchas de las funciones de la música en la sociedad venda que he descrito les recordará si- tuaciones similares en otras sociedades. Mi argumento general ha sido que, si se puede calcular el valor de la música dentro de la sociedad y la cultura, éste debe ser descrito en términos de las actitudes y los procesos cognitivos involucrados en su creación y de las funciones y los efectos del producto musical en la sociedad. De aquí se desprende que deban existir relaciones estructurales cercanas entre la función, el contenido y la forma de la música.

Robert Kauffman me ha mostrado un pasaje del libro Blues People, de LeRoi Jones (William Morrow, Nueva York, 1963), donde sostiene que la hipótesis de ese libro se basa en entender que "la música puede verse como el resultado de ciertas actitudes, ciertas formas de concebir el mundo, y sólo al final, como las formas en las que se hace la música” (p. 153). Es suficiente con que esto sea dicho y aceptado. Pero creo que sería útil si este argumento se reforzara con ejemplos de cómo funciona en la práctica. Esto es algo que los etnomusicólogos pueden lograr, y la mayor parte de mi trabajo de los últimos 15 años ha estado dirigida hacia el descubrimiento de las relaciones estructurales entre la música y la vida social. 